J. Dairy Sci. 95:5561-5568

http://dx.doi.org/10.3168/jds.2012-5486

(C) American Dairy Science Association ${ }^{\circledR}, 2012$.

\title{
The stretchability of Mozzarella cheese evaluated by a temperature-controlled 3-prong hook test
}

\author{
X. Ma, ${ }^{*}$ B. James, ${ }^{*}$ L. Zhang, $†$ and E. A. C. Emanuelsson-Patterson $\ddagger^{1}$ \\ *Department of Chemical and Materials Engineering, University of Auckland, Auckland 1142, New Zealand \\ †Fonterra Research Centre, Fonterra Co-operative Group Ltd., Palmerston North 4442, New Zealand \\ fDepartment of Chemical Engineering, University of Bath, Claverton Down, Bath BA2 7AY, United Kingdom
}

\section{ABSTRACT}

Stretchability is one of the most important functional properties of Mozzarella cheese, but no objective and widely accepted technique exists for evaluation; most of the cheese stretchability tests are influenced by the ambient conditions. This paper demonstrates a technique, which is novel and relatively simple, to evaluate the stretchability of Mozzarella cheese objectively. In an oil bath, melted cheese is stretched by a hook probe, controlled by an Instron tensile tester (Instron Corp., Norwood, MA); cheese strands are lifted from the melted cheese reservoir to a stretch length of 300 $\mathrm{mm}$, when the load and extension data are recorded by the Instron tensile tester. This test overcomes other tests' drawbacks, such as subjective stretching speeds and variations in ambient temperature and humidity. Through the test comparison on standard Mozzarella, the modified stretching test in an oil bath has greater repeatability than the original test without oil bath. From the load and extension curve, the yield load is measured to evaluate the stretchability. In the meantime, the inversion point extension of necking is also measured based on polymer study, producing more repeatable results than the yield load. The modified 3-prong hook test was applied to Mozzarella cheese samples with different processing conditions, including the screw conditions (screw time, speed, and temperature), draining $\mathrm{pH}$, calcium content, and fat content, and significant differences were found between these samples and the control sample.

Key words: Mozzarella, stretchability, yield load, inversion point extension

\section{INTRODUCTION}

Mozzarella is one of the most widely sold cheeses. Its main use is as a pizza topping because of its stretch-

\footnotetext{
Received February 28, 2012.

Accepted June 21, 2012.

${ }^{1}$ Corresponding author: eaep20@bath.ac.uk
}

ability, meltability, and shredability. Stretchability is defined as the ease and extent to which cheese strands are formed (Gunasekaran and Ak, 2003). During manufacture, Mozzarella cheese is stretched in hot water using a mechanical mixer with screws, which results in high stretchability because the proteins are aligned into fibers with the fat and the serum incorporated between the fibers (McMahon et al., 1993).

The stretching of polymers is analogous to the stretching of cheese. When some polymers are stretched uniformly for a few percent, they form a neck rather than break. Either the neck becomes steadily thinner until it breaks, or it stabilizes at some point and then propagates along the specimen (Vincent, 1960), which is often called cold drawing. In the stretching of cheese, neck thinning is combined with neck propagation as observed. Factors that are related to load and deformation before, during, and after the formation of a stable neck can be applied to distinguish the stretch profiles of different cheeses.

Researchers have developed a range of techniques to evaluate the stretchability of Mozzarella cheese. At a specific time after a pizza had been baked, the fork test measured the stretch length of cheese lifted by a fork until it broke (USDA, 1980). This method was fast and easily implemented, but the results were dependent on the individuals performing the test (specifically, the uncontrolled lifting speed, load, and other factors), which decreased the reproducibility. An improved method is the tensile stretch test; this is a more objective method, in which a circular piece of cheese is lifted vertically out of a baked cheese pizza at a constant speed (Apostolopoulos, 1994). The stretchability was defined as the point at which all cheese strands break off the pizza. Guinee and O'Callaghan (1997) cut a pizza base into 2 equal halves, before covering it with shredded cheese and baking. The cooked pizza was then placed on the platform of a stretching apparatus. The sides of the pizza were clamped and stretched apart until the extended strings of cheese broke completely (Guinee and O'Callaghan, 1997). 
To prevent the problems associated with temperature, humidity, and moisture loss and to increase the repeatability, the cheese was stretched in mineral oil using a uniaxial horizontal extension test ( $\mathrm{Ak}$ et al., 1993). A tensile tester stretched the dumbbell-shaped cheese sample by moving the clamp attached to the sample, at a constant speed. The limitation with this study was that the cheese samples could be evaluated only between 10 and $40^{\circ} \mathrm{C}$, because the cheese became soft and difficult to clamp at higher temperatures.

Instead of using clamps, Fife et al. (2002) used a 3 -prong hook method to provide a simple and objective way of measuring the stretchability of melted Mozzarella cheese using a tensile tester. A steel cup containing Mozzarella cheese was heated in a water bath and fixed on the platform of a tensile tester; once the temperature was uniform, the hook was inserted into the sample and the cheese was pulled vertically to obtain a load-distance curve. The main drawback with this technique was that the results were dependent on the environmental conditions such as temperature and humidity, resulting in poor repeatability. To overcome the drawbacks, the present study improved this method by performing the tensile test in a temperature-controlled oil bath. Oil has been used previously as a medium for the evaluation of cheese stretchability, to maintain a uniform temperature and to prevent the cheese from drying out (Ak et al., 1993; Hicsasmaz et al., 2004; Joshi et al., 2004), and has been shown not to affect the stretchability (Ak and Gunasekaran, 1995).

The aim of this study was, first, to verify whether stretching the cheese in oil would overcome the issue of poor reproducibility and second, to investigate the stretchabilities of Mozzarella cheeses of different compositions and manufactured using different processing conditions. In addition, based on this technique, parameters to evaluate the stretchability of Mozzarella cheese are to be defined.

\section{MATERIALS AND METHODS}

\section{Three-Prong Hook Test}

A double-walled glass cylinder (Figure 1), which allowed hot water to circulate between the glass walls to control the temperature, was built. The height was $350 \mathrm{~mm}$ and the internal diameter was $50 \mathrm{~mm}$. Plugs $(21 \pm 0.3 \mathrm{~g})$ cut from Mozzarella cheese blocks were placed in separate beakers (with a diameter of $36 \mathrm{~mm}$ and a height of $50 \mathrm{~mm}$ ), covered with aluminum foil to prevent water evaporation, and heated in a water bath for $30 \mathrm{~min}$ at 70 or $90^{\circ} \mathrm{C}$. Individually, beakers containing melted cheese were put into the bottom of the glass

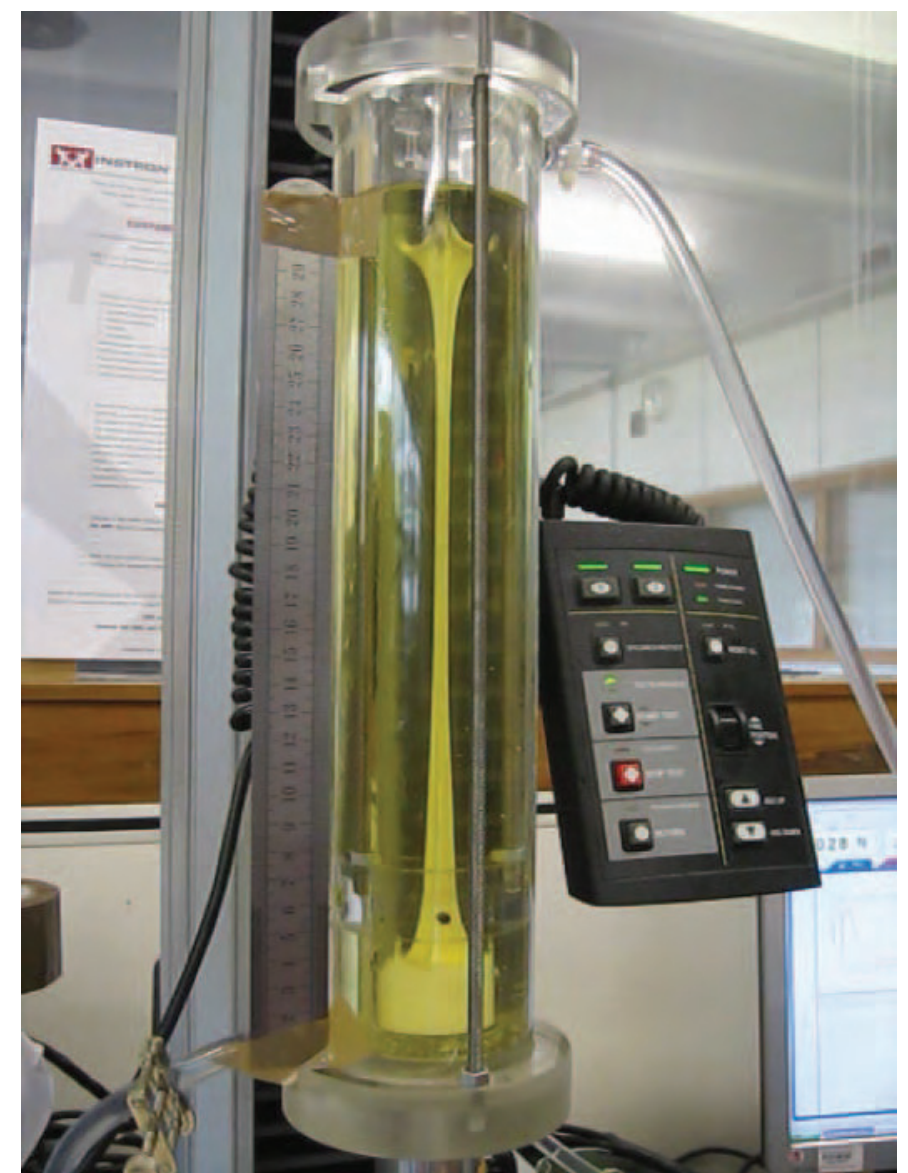

Figure 1. Modified 3-prong hook stretching test. Color version available in the online PDF.

cylinder, which contained the oil already heated to the appropriate temperature. A 3-prong hook connected to a tensile tester (Instron 5543; Instron Corp., Norwood, MA) was inserted into the melted cheese until it was $5 \mathrm{~mm}$ from the bottom of the beaker. The hook lifted cheese strands at a speed of $1,000 \mathrm{~mm} / \mathrm{min}$ to a distance of $300 \mathrm{~mm}$ (Fife et al., 2002).

To test for repeatability, defined as the variation in measurements taken by the same person or instrument on the same item and under the same conditions, 3 -prong hook tests with and without an oil bath (at 70 or $90^{\circ} \mathrm{C}$ ) were performed on a Mozzarella cheese (Fonterra Brands Ltd., Conifer Grove, Takanini, Auckland) bought from a local supermarket at each set of conditions with 9 replications. Mozzarella cheeses with different compositions and manufactured using different processing conditions were produced at the Fonterra Research Centre (Palmerston North, New Zealand). Samples of these cheeses were tested using the 3-prong hook test, with the oil bath at $70^{\circ} \mathrm{C}$ and with 3 replications for each of them. 


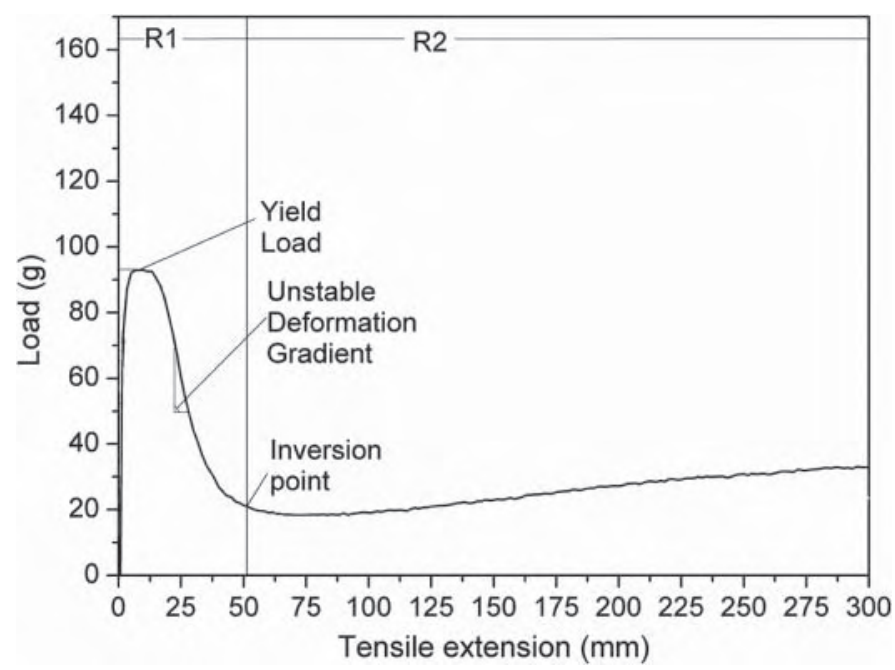

Figure 2. Parameters to evaluate the stretch profile of cheese. R1 $=$ the region in which the load increases until the hook has traveled around $10 \mathrm{~mm}$ and then decreases rapidly during an unstable deformation period as the hook leaves the cheese reservoir; the cheese finally forms a stable neck and the rate of the change in load decreases. R2 $=$ the region that starts at the inversion point, when the stable neck has formed, and the load increases gradually until the end of the test.

\section{Stretch Profile}

A load-extension curve (i.e., the stretch profile) for a sample of Mozzarella cheese is shown in Figure 2; it can be divided into 2 regions. In region R1, the load increases until the hook has traveled around $10 \mathrm{~mm}$ and then decreases rapidly during an unstable deformation period as the hook leaves the cheese reservoir. The cheese finally forms a stable neck and the rate of the change in load decreases. Region R2 starts at the inversion point, when the stable neck has formed, and the load increases gradually until the end of the test.

The maximum load of the cheese stretch profile is defined as the yield load. The slope of the dramatic decrease in load is defined, in this study, as the unstable deformation gradient (UDG) and relates to the rapid formation of the stable neck that propagates in R2. This is analogous to polymer stretching, when a stable neck forms during a tensile test after a region of rapid load or stress drop (Nazarenko et al., 1994). The load and extension values at the inversion point provide further parameters for quantifying stretchability.

\section{Microstructure}

Confocal laser scanning microscopy was used to examine the microstructure of the cheese samples. Mozzarella cheese samples were sectioned into slices $50-\mu \mathrm{m}$ thick using a cryotome (Leica CM1850; Leica Microsystems Inc., Buffalo Grove, IL), soaked in a $0.2 \%$ (wt/wt) Nile blue fluorescent probe (Sigma-Aldrich, St Louis,
MO), diluted in Citifluor to prevent photobleaching, and placed between a slide and a coverslip overnight. Images were taken using a confocal microscope with 40× objective (Leica TCS SP2; Leica Microsystems Inc.). A confocal laser scanning microscopy laser wavelength of 488 and $633 \mathrm{~nm}$ was used to excite the Nile blue used for fat and protein staining, with an emission wavelength of 514 and $645 \mathrm{~nm}$ individually for fat and protein. Samples from interrupted stretching tests were taken at extensions of 100, 150, 200, and $300 \mathrm{~mm}$.

\section{Manufacturing and Analysis of Different Mozzarella Cheese Samples}

Mozzarella cheese samples were manufactured at the Fonterra Research Centre (Fonterra Co-operative Group Limited, Palmerston North, New Zealand) with different processing conditions. The control sample was produced using standard processing conditions (CT); samples were also manufactured with long screw time (ST), high screw speed (SPD), high screw temperature (TM), both high screw speed and high screw temperature (TMP), low draining $\mathrm{pH}(\mathbf{L P H})$, high draining $\mathrm{pH}(\mathbf{H P H})$, high calcium content $(\mathbf{H C A})$, high fat content (HFT), and low fat content (LFT); the detailed processing conditions are shown in Table 1.

Fresh milk was standardized to a protein-fat ratio of 1.31 (except 0.71 for HFT and 3.49 for LFT; $19.8 \mathrm{~g} / \mathrm{kg}$ of $\mathrm{CaCl}_{2}$ was added to the milk for HCA). The milk was pasteurized, cultured (with mesophilic starter culture), stirred, and let stand for $15 \mathrm{~min}$. The curd was cut, and then whey was drained when $\mathrm{pH}$ decreased to 5.9 (except 5.8 for LPH and 6.1 for $\mathrm{HPH}$ ). Then the curd was milled (at $\mathrm{pH}$ of 5.3), salted, and dry stirred. A twin screw was used to stretch the curd with a speed of $17.6 \mathrm{rpm}$ (except $20.8 \mathrm{rpm}$ for SPD) in hot water at $58^{\circ} \mathrm{C}$ (except $68^{\circ} \mathrm{C}$ for TMP and ST) for 2 min (except $10 \mathrm{~min}$ for $\mathrm{TM}$; the total transit time from the point when the curd entered the mixer to when it exited). Samples were vacuum-packed and stored at $4^{\circ} \mathrm{C}$, and their stretchabilities were analyzed after $12 \mathrm{wk}$ of aging.

The compositions of the cheeses were confirmed using several techniques. Fat content and moisture content were determined using a FoodScan dairy analyzer (Foss Electric A/S, Hillerød, Denmark). Salt content was measured using an autotitrator (Metrohm Ltd., Herisau, Switzerland) and calcium content was measured using inductively coupled plasma optical emission spectrometry (Varian Ltd., Palo Alto, CA). To measure noncasein nitrogen (NCN) content, the cheese was dissolved using $1 \mathrm{~mL}$ of $0.1 \mathrm{M} \mathrm{NaOH}$, and then 2 $\mathrm{mL}$ of acetic acid solution was added. Once the filtrates were prepared, the nitrogen content was determined using the Kjeldahl method (BOCHI Kjeldahl; BUCHI 
Table 1. Chemical compositions of Mozzarella cheese samples manufactured using different processing conditions

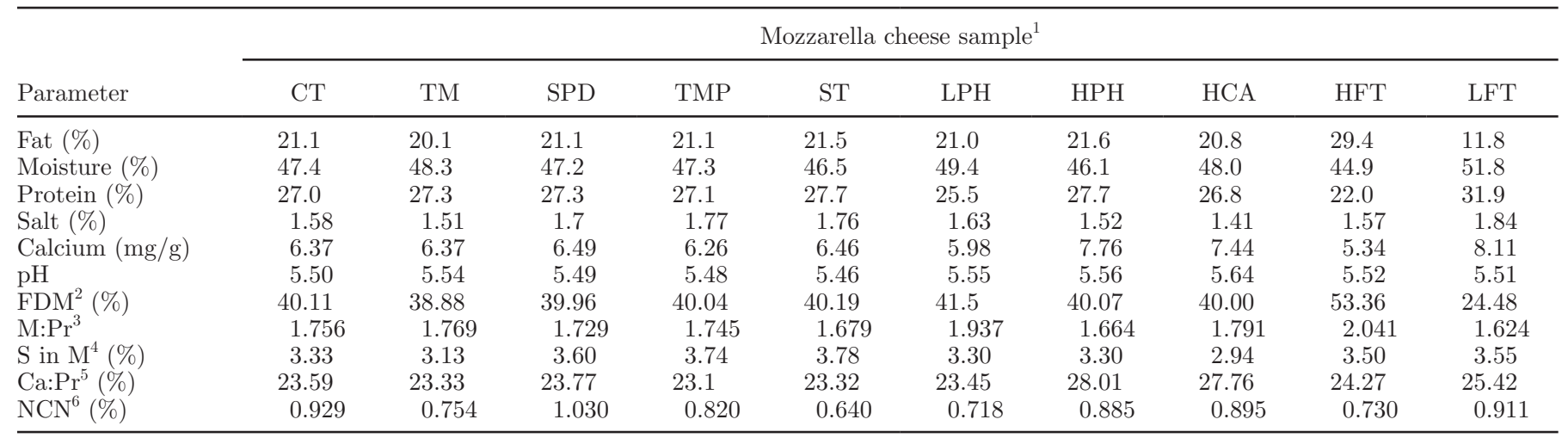

${ }^{1} \mathrm{CT}=$ control processing conditions; $\mathrm{TM}=$ long screw time; $\mathrm{SPD}=$ high screw speed; TMP $=$ high screw temperature; $\mathrm{ST}=$ high screw speed and high screw temperature; $\mathrm{LPH}=$ low draining $\mathrm{pH} ; \mathrm{HPH}=$ high draining $\mathrm{pH} ; \mathrm{HCA}=$ high calcium content; HFT = high fat content; LFT $=$ low fat content

${ }^{2}$ Fat in DM.

${ }^{3}$ Ratio between moisture content and protein content.

${ }^{4} \mathrm{~S}$ in $\mathrm{M}=$ salt in moisture.

${ }^{5}$ Ratio between calcium content and protein content.

${ }^{6}$ Noncasein nitrogen.

Labortechnik AG, Flawil, Switzerland). All chemical analyses were carried out by the Analytical Services Group at the Fonterra Research Centre.

\section{Statistical Analysis}

One-way ANOVA was performed to investigate the significant difference between cheese samples with different compositions and manufacturing conditions using OriginPro 8 software (OriginLab Corp., Northampton, MA).

\section{RESULTS}

\section{Stretching Test With and Without an Oil Bath}

Table 2 shows that the 3 parameters of stretchability under the conditions with oil bath had obviously lower standard deviation percentages than those without oil bath at the same temperature, except that the standard deviation percentages of yield load at $70^{\circ} \mathrm{C}$ with and without oil bath were similar. In addition, for the tests with oil bath, the standard deviation percentages at $90^{\circ} \mathrm{C}$ were less than those at $70^{\circ} \mathrm{C}$. However, the higher-temperature oil bath significantly decreased the yield load, which inevitably lowered the differences in yield load between different cheese samples. Therefore, for the Mozzarella cheeses of different compositions and manufactured using different processing conditions, the stretching test with the oil bath at $70^{\circ} \mathrm{C}$ was applied.

The microstructures of standard Mozzarella cheese samples at various extensions are shown in Figure 3. It is clear that the anisotropy of the protein strands was maintained during this extension and that no substantial breakdown of the structure occurred.

Table 2. Repeatability of stretchability test for Mozzarella under different test conditions

\begin{tabular}{|c|c|c|c|c|}
\hline \multirow[b]{3}{*}{ Parameter } & \multicolumn{4}{|c|}{ Test conditions } \\
\hline & \multicolumn{2}{|c|}{ Without oil bath } & \multicolumn{2}{|c|}{ With oil bath } \\
\hline & $70^{\circ} \mathrm{C}$ & $90^{\circ} \mathrm{C}$ & $70^{\circ} \mathrm{C}$ & $90^{\circ} \mathrm{C}$ \\
\hline Yield load (g) & 298.94 & 82.71 & 146.09 & 68.39 \\
\hline SD (\%) & 16.1 & 20.4 & 16.3 & 17.0 \\
\hline Unstable deformation gradient $(\mathrm{g} / \mathrm{mm})$ & 4.90 & 0.92 & 4.41 & 1.92 \\
\hline SD $(\%)$ & 62.9 & 78.3 & 24.0 & 14.6 \\
\hline Inversion point extension (mm) & 61.00 & 53.00 & 50.78 & 47.67 \\
\hline $\mathrm{SD}(\%)$ & 19.0 & 14.1 & 17.7 & 9.1 \\
\hline
\end{tabular}




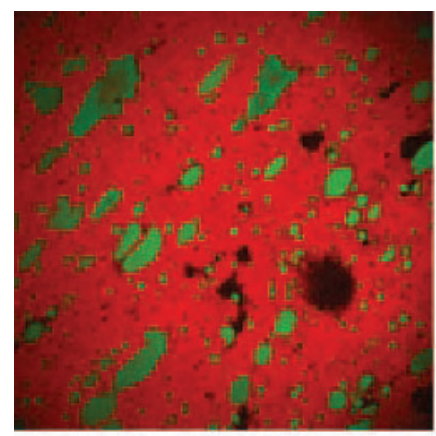

(a)

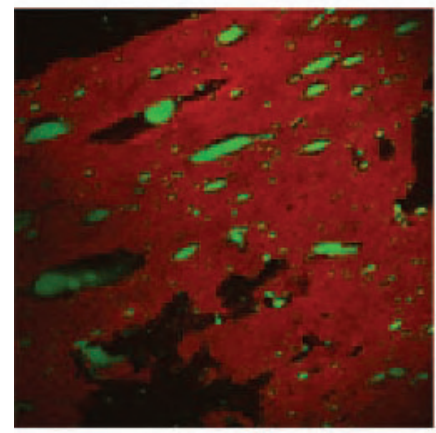

(c)

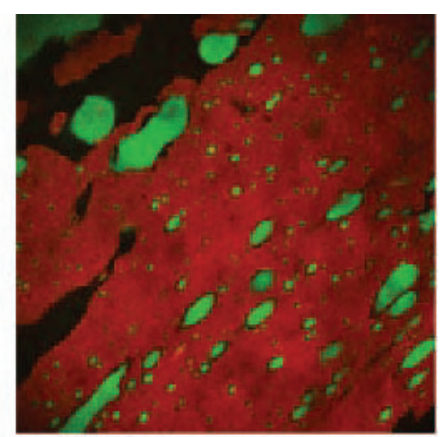

(b)

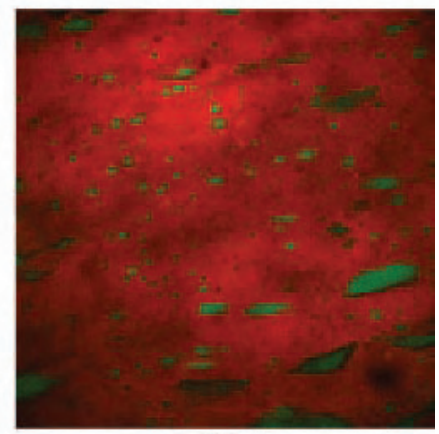

(d)
Figure 3. Confocal laser scanning microscopy microstructures of standard Mozzarella cheese during a stretching test at extensions of (a) $100 \mathrm{~mm}$, (b) $150 \mathrm{~mm}$, (c) $200 \mathrm{~mm}$, and (d) $300 \mathrm{~mm}$. Color version available in the online PDF.

\section{Stretch Profiles of Mozzarella Cheese Samples}

The stretch profiles of the different Mozzarella cheese samples in the $70^{\circ} \mathrm{C}$ oil bath are shown in Figure 4, in which substantial differences among the yield loads and the inversion points of the different samples can be found.

The parameters yield load, UDG, and inversion point are shown in Figures 5, 6, and 7, respectively. Figure 5 shows that the largest difference in yield load was between LFT and HFT, with values of 328 and $49 \mathrm{~g}$, respectively. High draining $\mathrm{pH}$ and $\mathrm{HCA}$ had similar yield load values $(P>0.05)$, and both higher than that of CT $(P<0.05)$, whereas LPH had a similar yield load value to $\mathrm{CT}(P>0.05)$. Among the samples manufactured using different screw conditions, only SPD had a lower yield load than CT $(P<0.05)$; TMP, TM, and ST had increased yield loads $(P<0.05)$.

Figure 6 shows that the UDG of SPD and HFT were lower, and the UDG of TMP, ST, HPH, and LFT were higher than that of CT $(P<0.05)$. The UDG of TM, $\mathrm{LPH}$, and HCA did not differ from that of CT $(P>$ $0.05)$. Figure 7 shows that the inversion point extension values of all samples were higher than that of $\mathrm{CT}(P<$ 0.05 ) except SPD (lower than CT, $P<0.05$ ) and HFT (not significantly different from CT, $P>0.05$ ).

\section{DISCUSSION}

\section{Modified Stretching Test}

The high variability of the load-extension curves that were produced during the stretching test without the oil bath was due to the rapid decrease in temperature and the dramatic moisture loss of the cheese strands when stretched in air. The modified stretching test overcomes these problems with the temperature-controlled oil bath, which provides a uniform environment with a constant temperature, preventing temperature decrease and moisture loss.

\section{Stretchability of Mozzarella Cheese Samples}

Both the yield load and the inversion point can be used to quantify stretchability. The yield load reflected the cheese viscosity and its capacity to resist deformation (Fife et al., 2002). The inversion point indicates the extension at which a stable neck is formed, after which the material stretches uniformly with apparent strain hardening.

Calcium acts as a cementing agent that cross-links and, thus, strengthens the casein network. A cheese with a higher calcium content has been found to require higher loads when using a uniaxial horizontal extension test (Joshi et al., 2004), which was corroborated by our results. Calcium content has been found to control the stretchability of nonfat Mozzarella cheese (McMahon et al., 2005); in the current study, both HPH and HCA, with higher calcium content (see Table 1), had higher yield load than $\mathrm{CT}$.

The high yield load of LFT was probably due to its lower fat content and higher protein content, in addition to its higher calcium content, compared with CT. This is in agreement with previous literature; low-fat cheese has fewer and smaller fat globules embedded in the protein matrix than full-fat cheese, and the dominating protein matrix results in the firm texture of low-fat cheese (Mistry and Anderson, 1993). Even though LFT had low fat, and no butter oil was added on the surface during heating in the water bath, surface cooling and desiccation were minimized by its natural free oil formation, due to the aging effect (Kindstedt and Kiely, 1992).

Cheese manufactured under SPD was compositionally similar to CT cheese in terms of fat, moisture, and protein content; this was in contrast to other research 
(Renda et al., 1997), in which differences in moisture content and protein content were related to the screw speed (this was probably because the screw speed for SPD in the current study was only slightly higher than that for CT). However, it should be noted that SPD had a significantly higher NCN content, which is an index of proteolysis, indicating that SPD had higher protein degradation than CT. As a result, SPD had a less dense casein structure than CT, which explains its lower yield load. Similarly, TM, TMP, and ST, with higher NCN, had higher yield loads than CT.

The UDG and inversion point extension results were similar to the yield load results. In addition to the stretchability of the cheese, the UDG is also affected by how much the cheese was lifted by the hook, as indicated by the higher UDG value for HPH than for HCA. This difference in the amount of cheese lifted by the hook results in relatively high standard deviations of UDG, which is a limit to this parameter. The inversion point extension results had smaller standard deviations than the yield load results, indicating that, compared with yield load, the inversion point extension is a more repeatable parameter for the evaluation of stretchability and can distinguish smaller differences between the stretchabilities of Mozzarella cheese samples.

Consumers may have different preferences regarding the stretchability of Mozzarella cheese. The higher values of yield load and inversion point extension, respectively, indicate that it is more difficult to stretch the cheese, and it takes longer for the cheese strings to be stable. As a result, Mozzarella samples with lower yield load and inversion point extension values have greater stretchability.

\section{CONCLUSIONS}

The modified 3-prong hook stretching tests with oil bath had better repeatability than the same tests without oil bath. Yield load was selected for the evaluation of cheese stretchability. Because a similar necking phenomenon to that observed for some polymers occurred in the stretching test, the inversion point extension was also measured. Both increasing the calcium content and increasing the draining $\mathrm{pH}$ increased the yield load. Compared with a control sample, a high-fat Mozzarella had around $70 \%$ of the yield load, and a low-fat Mozzarella had a yield load 3 times higher. Mozzarella cheeses manufactured using a long screw time or a high screw temperature had a higher yield load, and those manufactured using a high screw speed had lower yield load. As the inversion point extension and the yield load results behaved similarly, both parameters can be used to quantify the stretchability of cheese using this temperature-controlled 3-prong hook test.

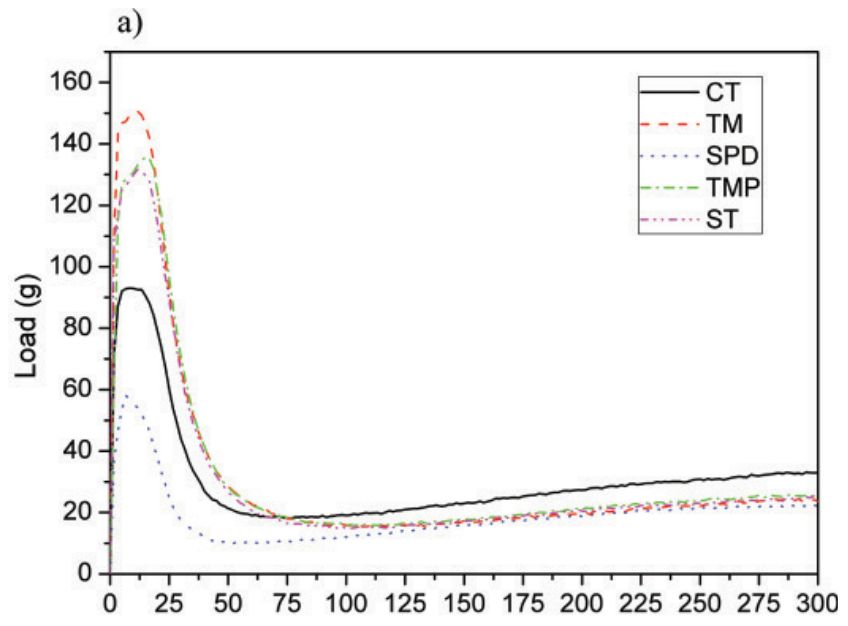

b)
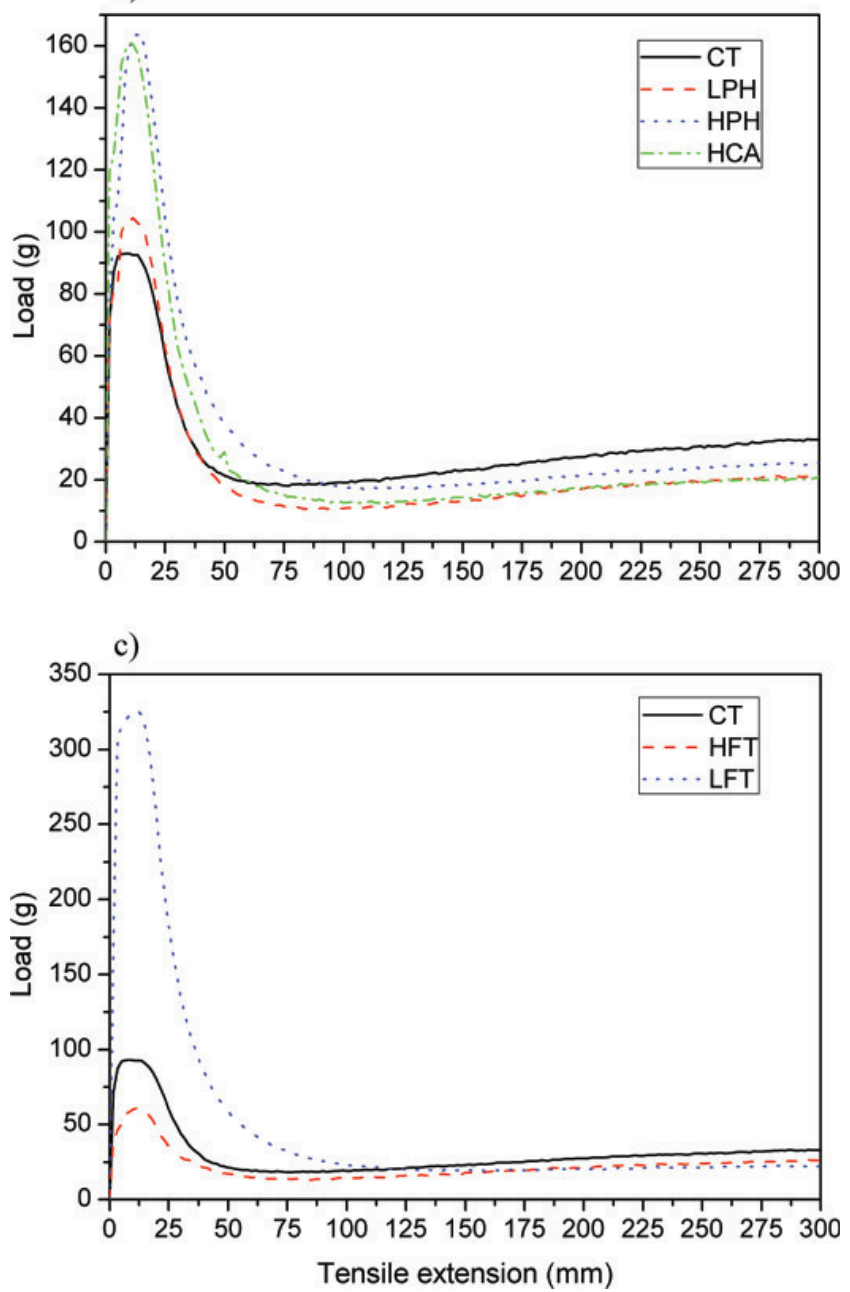

Figure 4. Stretch profiles of Mozzarella cheese samples manufactured using different processing conditions: control processing conditions (CT), long screw time (TM), high screw speed (SPD), high screw temperature (TMP), high screw speed and high screw temperature (ST), low draining $\mathrm{pH}(\mathrm{LPH})$, high draining $\mathrm{pH}(\mathrm{HPH})$, high calcium content (HCA), high fat content (HFT), and low fat content (LFT). Color version available in the online PDF. 


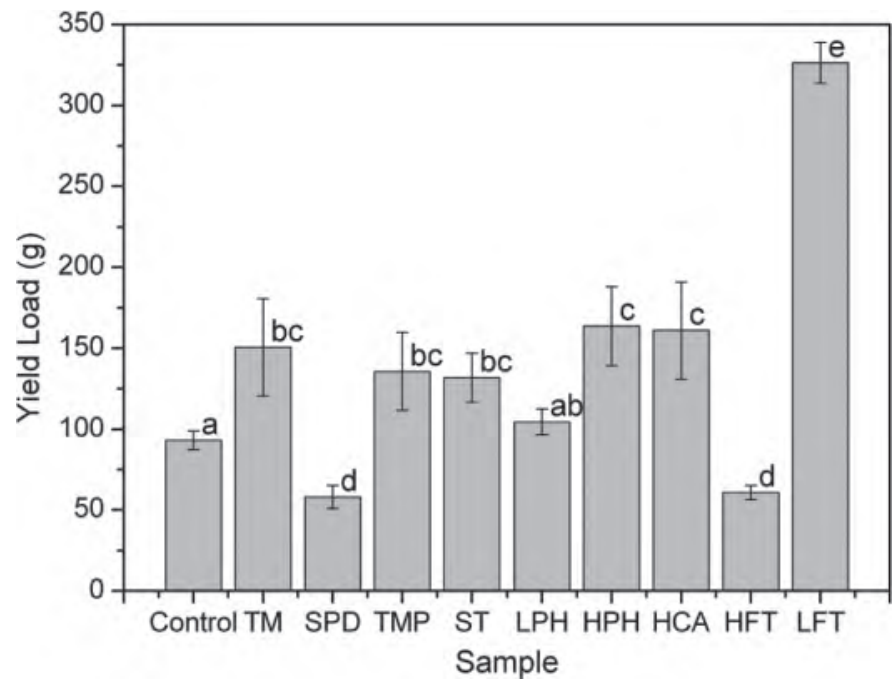

Figure 5. Yield load of Mozzarella cheese samples manufactured using different processing conditions: control processing conditions (CT), long screw time (TM), high screw speed (SPD), high screw temperature (TMP), high screw speed and high screw temperature (ST), low draining $\mathrm{pH}(\mathrm{LPH})$, high draining $\mathrm{pH}(\mathrm{HPH})$, high calcium content (HCA), high fat content (HFT), and low fat content (LFT). The error bars represent the standard deviation and the yield loads with different letters $(\mathrm{a}-\mathrm{e})$ are significantly different $(P<0.05)$.

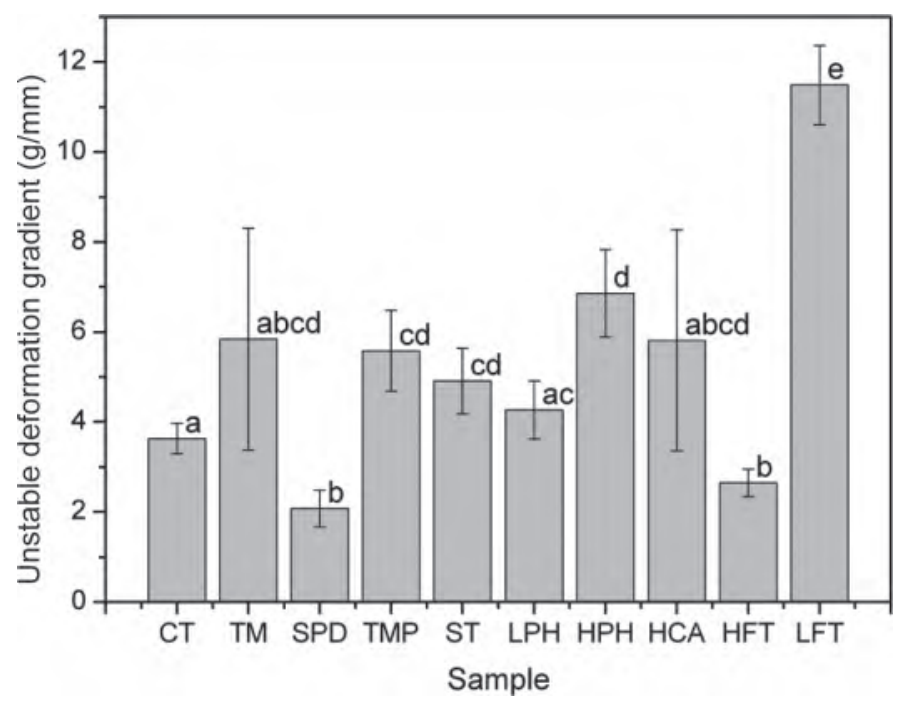

Figure 6. Unstable deformation gradient of Mozzarella cheese samples manufactured using different processing conditions: control processing conditions $(\mathrm{CT})$, long screw time (TM), high screw speed (SPD), high screw temperature (TMP), high screw speed and high screw temperature (ST), low draining $\mathrm{pH}(\mathrm{LPH})$, high draining $\mathrm{pH}$ $(\mathrm{HPH})$, high calcium content (HCA), high fat content (HFT), and low fat content (LFT). The error bars represent the standard deviation and the unstable deformation gradients with different letters (a-e) are significantly different $(P<0.05)$.

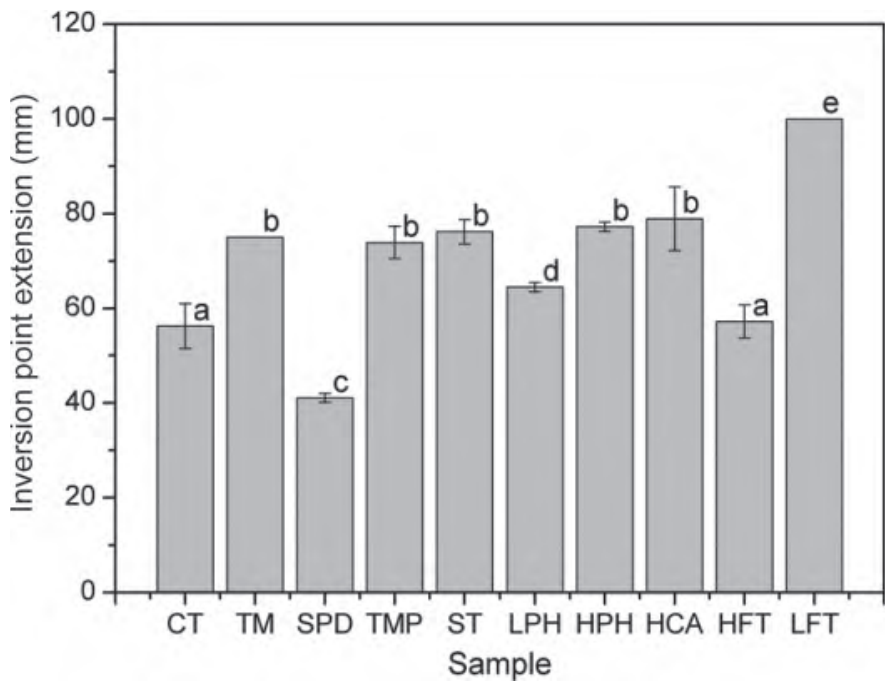

Figure 7. Inversion point extension of Mozzarella cheese samples manufactured using different processing conditions: control processing conditions (CT), long screw time (TM), high screw speed (SPD), high screw temperature (TMP), high screw speed and high screw temperature $(\mathrm{ST})$, low draining $\mathrm{pH}(\mathrm{LPH})$, high draining $\mathrm{pH}(\mathrm{HPH})$, high calcium content (HCA), high fat content (HFT), and low fat content (LFT). The error bars represent the standard deviation, and the inversion point extensions with different letters (a-e) are significantly different $(P<0.05)$.

\section{ACKNOWLEDGMENTS}

The project funding was jointly supported by Fonterra Co-operative Group Ltd. (Palmerston North, New Zealand) and the Chinese Scholarship Council (Beijing, China). We gratefully acknowledge Fonterra Research Centre for the cheese making and chemistry analysis. We appreciate the technical assistance of Raymond Hoffman, Hilary Holloway, Xudong Feng, Ashvin Thambyah, Michael Hodgson (all of the University of Auckland), and the glass workshop at the University of Auckland (Auckland, New Zealand), and Andrew Huxford, Bruce Allen, Elizabeth Nickless, and Errol Conaghan at Fonterra Research Centre.

\section{REFERENCES}

Ak, M. M., D. Bogenrief, S. Gunasekaran, and N. F. Olson. 1993. Rheological evaluation of Mozzarella cheese by uniaxial horizontal extension. J. Texture Stud. 24:437-453.

Ak, M. M., and S. Gunasekaran. 1995. Measuring elongational properties of Mozzarella cheese. J. Texture Stud. 26:147-160.

Apostolopoulos, C. 1994. Simple empirical and fundamental methods to determine objectively the stretchability of Mozzarella cheese. J. Dairy Res. 61:405-413.

Fife, R. L., D. J. McMahon, and C. J. Oberg. 2002. Test for measuring the stretchability of melted cheese. J. Dairy Sci. 85:3539-3545.

Guinee, T. P., and D. J. O'Callaghan. 1997. The use of a simple empirical method for objective quantification of the stretchability of cheese on cooked pizza pies. J. Food Eng. 31:147-161.

Gunasekaran, S., and M. M. Ak. 2003. Cheese Rheology and Texture. CRC Press, Boca Raton, FL. 
Hicsasmaz, Z., L. Shippelt, and S. S. H. Rizvi. 2004. Evaluation of Mozzarella cheese stretchability by the ring-and-ball method. J. Dairy Sci. 87:1993-1998.

Joshi, N. S., K. Muthukumarappan, and R. I. Dave. 2004. Effects of reduced-calcium, test temperature and storage on stretchability of part-skim Mozzarella cheese. Aust. J. Dairy Technol. 59:60-65.

Kindstedt, P. S., and L. J. Kiely. 1992. Revised protocol for the analysis of melting properties of Mozzarella cheese by helical viscometry. J. Dairy Sci. 75:676-682.

McMahon, D. J., C. J. Oberg, and W. McManus. 1993. Functionality of Mozzarella cheese. Aust. J. Dairy Technol. 48:99-104.

McMahon, D. J., B. Paulson, and C. J. Oberg. 2005. Influence of calcium, pH, and moisture on protein matrix structure and functionality in direct-acidified nonfat Mozzarella cheese. J. Dairy Sci. $88: 3754-3763$
Mistry, V. V., and D. L. Anderson. 1993. Composition and microstructure of commercial full-fat and low-fat cheeses. Food Struct. $12: 259-266$.

Nazarenko, S., S. Bensason, A. Hiltner, and E. Baer. 1994. The effect of temperature and pressure on necking of polycarbonate. Polymer (Guildf.) 35:3883-3892.

Renda, A., D. M. Barbano, J. J. Yun, P. S. Kindstedt, and S. J. Mulvaney. 1997. Influence of screw speeds of the mixer at low temperature on characteristics of Mozzarella cheese. J. Dairy Sci. 80:1901-1907.

USDA (US Department of Agriculture). 1980. USDA Specifications for Mozzarella Cheeses. Agric. Marketing Service, USDA, Washington, DC.

Vincent, P. I. 1960. The necking and cold-drawing of rigid plastics. Polymer (Guildf.) 1:7-19. 